\title{
Os significados do não aprender na sala de apoio à aprendizagem: resiliência em processo
}

\author{
Jane Ester da Silva Bazoni \\ Francismara Neves de Oliveira \\ Universidade Estadual de Londrina
}

\section{Resumo}

A abordagem bioecológica de Bronfenbrenner foi adotada como aporte teóricometodológico neste trabalho, que objetivou analisar possíveis inter-relações entre dois microssistemas - família e escola -, no que diz respeito ao modo como é compreendido o não aprender na sala de apoio à aprendizagem (SAA). A pesquisa teve como lócus uma escola da rede estadual de ensino da cidade de Londrina/PR. Participaram do estudo 36 sujeitos, assim distribuídos: treze alunos, treze representantes das famílias (um de cada família), três pedagogas, duas professoras da sala de apoio e cinco professores da sala regular. Adotamos como abordagem a pesquisa qualitativa, de cunho descritivo, na modalidade de estudo de caso. Como instrumento para a coleta de dados, utilizamos a observação sistemática (doze encontros realizados uma vez por semana, durante três meses) e entrevista aos participantes, na modalidade semiestruturada. 0 estudo envolveu a análise dos microssistemas escolar e familiar, destacando as possíveis intersecções entre eles na significação do não aprender, e levou em conta que as significações estão permeadas por mecanismos de risco e proteção. Nossos resultados indicaram a importância de dar voz aos protagonistas dos microssistemas nos quais a sala de apoio está ancorada, a fim de compreender como o processo de aprendizagem desses alunos é permeado por interações que promovem significados às experiências. Os dados nos convidam a reconhecer que o não aprender constitui risco diante do qual os fatores protetivos-resiliência podem se manifestar.

Palavras-chave: Resiliência. Não aprender. Risco. Proteção. Teoria bioecológica. 


\section{The imports of not learning in the learning support room: resilience in process}

The Bronfenbrenner bioecological approach was adopted as a theoretical-methodological contribution in this study, the aim of which is to analyze possible interrelationships between two microsystems - family and school, concerning how not learning is understood in the Learning Support Room (LSR). The locus of this research is a public school in Londrina, Parana, Brazil. The study included 36 subjects, thus distributed: thirteen students, thirteen representatives of families (one from each family), three educators, two teachers from the learning support room, and five from the regular classroom. We adopted a qualitative research approach, descriptive in nature, in the case study modality. As a data collection tool, we utilized systematic observation: (twelve meetings held once a week for three months) and semi-structured interviews of participants. The study involved analysis of the school and family microsystems, highlighting possible intersections between them in the signification of not learning, considering that, imports are permeated by risk and protection mechanisms. Our results indicated the importance of giving voice to the protagonists of the microsystems on which the learning support room is anchored, in order to understand how the learning process of these students is permeated by interactions that promote meanings of life experiences. The data invite us to recognize that not learning constitutes a risk in face of which protective factors and resilience can be manifested.

Keywords: Education. Resilience. Not learning. Meaning. Bioecological theory.

\section{El significado desde el no aprender en la sala de apoyo hacia el aprendizaje: resiliencia en proceso}

El abordaje bioecológica de Bronfenbrenner fue adoptado como aporte teórico metodológico en este trabajo cuyo objetivo fue analizar interrelaciones posibles entre dos microsistemas familia y escuela, en lo que se refiere al modo como es comprendido el no aprender en el Aula de Apoyo al Aprendizaje (SAA por sus siglas en portugués). La investigación tuvo como lócus una escuela de la red estatal de enseñanza de la ciudad de Londrina, Paraná. Participaron del estudio 36 sujetos, distribuidos a saber: trece alumnos, trece representantes de las familias (uno de cada familia), tres pedagogas, dos profesoras del aula de apoyo y cinco profesores del aula regular. Adoptamos como abordaje una investigación cualitativa, de cuño descriptivo en la modalidad de estudio de caso. Como instrumento para la recolección de datos, utilizamos la observación sistemática (doce encuentros realizados una vez por semana, durante tres meses) y entrevista a los participantes, en la modalidad semiestructurada. El estudio envolvió el análisis de los microsistemas escolar y familiar; destacando las posibles intersecciones entre ellos en el significado de no aprender y tomó en cuenta que los significados están permeabilizados por mecanismos de riesgo y protección. Nuestros resultados indicaron la importancia de dar voz a los protagonistas de los microsistemas en los cuales la sala de apoyo está basada, afín de comprender como el proceso de aprendizaje de esos alumnos está permeabilizado por interacciones que promueven significados a las experiencias. Los datos nos invitan a reconocer que el no aprender constituye un riesgo delante del cual los factores protectores-resilencia se pueden manifestar.

Palabras-clave: Resiliencia. No aprender. Riesgos. Protección. Teoría bioecológica. 


\section{Introdução: apresentação do cenário da pesquisa}

Dar voz aos protagonistas envolvidos em um programa de apoio à aprendizagem escolar, inserido nas políticas públicas educacionais do governo estadual paranaense, constituiu o estudo que apresentamos. A SAA é um programa do Governo do Estado do Paraná que busca desenvolver ações para o enfrentamento dos problemas relacionados à aprendizagem dos alunos nos conteúdos básicos das disciplinas de língua portuguesa (oralidade, leitura, escrita) e matemática (formas espaciais, operações básicas e elementares). (Paraná, 2011)

0 problema norteador da pesquisa foi assim delineado: quais os modos de significar o não aprender presentes no contexto da sala de apoio à aprendizagem? Que relações são possíveis estabelecer entre os mecanismos de risco e proteção presentes no contexto investigado e os modos de significar o não aprender? A problemática está ancorada na compreensão do conceito de resiliência, pautado na abordagem bioecológica do desenvolvimento humano, aporte teórico deste estudo.

Os princípios centrais desta teoria consideram que o desenvolvimento consiste em um processo de interação recíproca entre a pessoa e seu contexto, através do tempo, por meio de múltiplas relações (Bronfenbrenner, 1996, 2011). Na opinião de Yunes (2001), é uma abordagem teórica que auxilia a compreensão da complexidade do fenômeno da resiliência, pois considera a interação dinâmica entre aspectos individuais e ambientais.

Conforme Ceconello (2003), a resiliência em situação de não aprendizagem escolar engendra mecanismos de risco e de proteção, e, portanto, considera-se pertinente identificar os fatores de risco e proteção no processo da sala de apoio à aprendizagem.

0 estudo destas questões suscitou como objetivo: analisar as inter-relações existentes entre dois microssistemas: família e escola, acerca do não aprender na sala de apoio à aprendizagem, considerando os significados atribuídos pelos protagonistas e relacionando-os aos mecanismos de risco e de proteção presentes neste contexto.

Para caracterizar o cenário da pesquisa realizada, ressaltamos que foi escolhida uma sala de apoio destinada ao trabalho com alunos pertencentes ao $6 .^{\circ}$ ano do ensino fundamental, que estão neste espaço por apresentarem dificuldades de aprendizagem e baixo rendimento escolar, em uma escola estadual no Município de Londrina-PR. Trata-se, então, do microssistema escolar eleito para este estudo, no qual interatuam mecanismos de risco e de proteção.

Apresentamos a seguir, de modo sucinto, os principais conceitos do modelo bioecológico do desenvolvimento humano utilizados para ancorar o conceito de 
resiliência e permitir a discussão sobre os mecanismos de risco e de proteção presentes no contexto da sala de apoio à aprendizagem escolar.

\section{Apontamentos teórico-metodológicos}

\section{Compreensão do processo a partir da teoria bioecológica de Bronfenbrenner}

0 desenvolvimento humano que é concebido neste campo teórico de maneira contextualizada revela a interação dinâmica entre quatro elementos: processo, pessoa, contexto e tempo (PPCT). (Bronfenbrenner, 1996, 2011). De acordo com o autor, o desenvolvimento consiste em um processo de interação recíproca entre a pessoa e o seu contexto através do tempo, por meio de múltiplas relações. Nessa linha de raciocínio, a resiliência revela-se como um processo que se inscreve em um contexto específico e reconstrói-se ao longo do tempo.

A interação recíproca não se limita a um ambiente único e imediato, mas envolve interconexões e influências externas oriundas de ambientes mais amplos que ocorrem ao longo do ciclo de vida da pessoa.

0 primeiro elemento do modelo bioecológico proposto por Bronfenbrenner (1996) é o processo, aspecto central, pois abrange formas particulares de interação entre o organismo e o ambiente imediato, denominadas processos proximais que operam ao longo de toda a vida do indivíduo e produzem resultados evolutivos no desenvolvimento. Podemos dizer que os processos proximais são os tipos de atividades do dia a dia em que as pessoas se engajam. (Yunes, 2001; Narvaz; Koller, 2004)

Diante disso, a interação da pessoa com o meio é caracterizada por reciprocidade. Os resultados evolutivos são compreendidos a partir da pessoa em desenvolvimento. Levam em conta suas características genéticas e aquelas que foram construídas na interação com o ambiente. Na opinião de Diniz e Koller (2010), o processo proximal mobiliza as características individuais da pessoa em desenvolvimento, bem como do ambiente no qual ela está inserida e do tempo em que os processos ocorrem. Os processos proximais funcionam como mecanismos primários de produção do desenvolvimento. No entanto, a exposição aos processos proximais pode variar de acordo com o desenrolar do tempo e das experiências da pessoa.

Dessa forma, além das características da pessoa e do ambiente no qual ela vive, os resultados evolutivos passam a ser vistos a partir da frequência do intervalo de tempo durante o qual ela foi exposta ao processo proximal e ao ambiente onde ele aconteceu. (Bronfenbrenner; Evans, 2000 apud Cecconello, 2003) 
O segundo elemento do modelo bioecológico PPCT é o estudo da pessoa, entendendo que as suas características são produtoras e produto do desenvolvimento. Dentre essas características, há três tipos que influenciam a direção e a força dos processos proximais e constituem os atributos pessoais: disposição, recursos e demandas. (Cecconello; Koller, 2000; Bronfenbrenner, 2011)

As disposições tanto podem colocar os processos proximais em movimento e sustentar sua operação, como interferir ativamente, retardar ou até impedir sua ocorrência. Por exemplo, características como a curiosidade e responsividade podem promover o desenvolvimento, enquanto características como impulsividade, distração e baixo nível de autoeficácia retardam o desenvolvimento.

Os recursos envolvem experiências, habilidades, conhecimentos adquiridos e as capacidades da pessoa que se desenvolvem no tempo e que são necessárias para o funcionamento eficaz dos processos proximais em determinado estágio de desenvolvimento.

As demandas são atributos pessoais inatos, como, por exemplo: gênero, etnia, temperamento, capazes de estimular ou inibir reações do ambiente social, favorecendo ou não o desenvolvimento dos processos proximais. 0 conjunto dessas características deve ser entendido como inerentes à pessoa e nenhuma delas exerce influência no desenvolvimento, de forma isolada. (Yunes, 2001; Santana; Koller, 2004; Poletto; Koller, 2008)

0 terceiro elemento do modelo bioecológico proposto por Bronfenbrenner (1996) é o contexto que é analisado pela interação de quatro níveis ambientais interdependentes. São eles: microssistema, mesossistema, exossistema e macrossistema, concebidos como uma organização de encaixe de estruturas concêntricas.

No nível mais interno do desenvolvimento, está o ambiente mais imediato da pessoa que pode ser a família, escola, sala de aula, grupo de amigos, áreas de lazer, denominado microssistema e dentro do qual ocorrem as interações face a face. (Brito, 1999; Borowsky, 2008; Antoni; Barone; Koller, 2006)

É importante dizer que as atividades, os papéis e as relações interpessoais são diferentes e específicas em cada ambiente e para cada pessoa, como, por exemplo, uma criança que assume papel de filho caçula em casa assume outro papel na escola. Além disso, mesmo que as atividades de uma pessoa estejam restritas ao ambiente imediato, elas podem se tornar mais complexas diante de outro elemento do microssistema por conta das relações com outras pessoas. Esse processo é constituído pelas "atividades molares", que são entendidas como formas de comportamentos percebidos de significado ou intenção pelos participantes do ambiente. 
Dessa forma, as atividades, os papéis e relações interpessoais experimentadas pela pessoa em desenvolvimento constituem elementos deste microssistema. Aqui, o termo "experienciado" é usado para indicar que as características do ambiente não são apenas as suas propriedades objetivas, mas também o modo como as pessoas percebem e atribuem significado a essas propriedades naquele ambiente (Bronfenbrenner, 1996; Krebs, 1995; Cecconello; Koller, 2000). Bronfenbrenner (1996, p. 19) ressalta: “[...] os aspectos do meio ambiente mais importantes na formação do curso do crescimento psicológico são, de forma esmagadora, aqueles que têm significado para a pessoa numa dada situação".

Contudo, o ambiente ecológico se estende muito além da situação imediata, envolvendo o mesossistema, que se refere ao vínculo formado a partir da interação entre dois ou mais ambientes nos quais a pessoa participa diretamente. (Bronfenbrenner, 1996, 2011; Brito, 1999; Cassol; Antoni, 2006). Entretanto não supõe interação face a face como é o caso do microssistema.

Santana e Koller (2004), Borowsky (2008) definem que o mesossistema consiste no conjunto de microssistemas que uma pessoa frequenta e as inter-relações estabelecidas por eles. Poletto (2011) expressa ainda que o mesossistema é ampliado sempre que uma pessoa passa a frequentar um novo ambiente.

0 exossistema, por sua vez, refere-se ao ambiente do qual a pessoa não participa diretamente, mas nele ocorrem eventos que afetam ou são afetados pelo ambiente imediato. (Bronfenbrenner, 1996; Morais, 2009)

Brito (1999), Santana e Koller (2004), Borowsky (2008) mencionam que o exossistema envolve ambientes nos quais o sujeito não está presente, mas os eventos que neles ocorrem influenciam indiretamente o desenvolvimento e delimitam o que acontece no ambiente mais próximo.

Por último citamos o macrossistema, no qual ocorrem as manifestações ideológicas e de organização de instituições sociais em uma cultura, num sistema de crenças, normas e valores da organização social. Para Bronfenbrenner (1996), a cultura, subcultura, as macroinstituições, como o governo federal e as políticas públicas, representam fenômenos do macrossistema.

Esse conjunto de crenças e valores que definem o macrossistema perpassa todos os outros três níveis da ecologia do desenvolvimento humano, "assim, a cultura na qual os pais foram educados, os valores e as crenças transmitidos por suas famílias de origem, bem como a sociedade atual onde eles vivem, interferem na maneira como eles educam seus filhos". (Cecconello, 2003, p. 16)

Portanto, olhar ecologicamente o desenvolvimento possibilita dirigir a atenção não só para a pessoa e os ambientes imediatos dos quais ela participa diretamente, mas considerar suas interações com os ambientes mais distantes dos quais ela participa indiretamente. (Poletto; Koller, 2008) 
0 quarto elemento do modelo bioecológico de desenvolvimento humano (PPCT) é o tempo. Ao analisar o elemento tempo, interessa focalizar a pessoa em relação aos acontecimentos presentes na sua vida, tanto os mais próximos, que fazem parte do cotidiano, quanto os mais distantes, que fazem parte da história de vida. (Narvaz; Koller, 2004; Poletto, 2008; Borowsky, 2008). Considerando esse elemento à luz da teoria bioecológica, para Prati (2009), o tempo exerce influência natural no desenvolvimento humano e é elemento fundamental na análise e constituição dos processos proximais.

A dimensão tempo representa um núcleo de análise que possui suas particularidades, como elencamos, mas seus processos estão sempre em interação dinâmica e integrada da pessoa, processo e contexto. Além disso, a flexibilidade e permeabilidade dos sistemas ecológicos são importantes para a promoção de resiliência. (Poletto; Koller, 2008)

Há que se levar em conta as peculiaridades das experiências vivenciadas pelo indivíduo em determinado contexto e não as diferenças encontradas na comparação com outros indivíduos que vivem contextos culturalmente desejáveis e esperados. Assim sendo, os significados atribuídos pela pessoa às vivências é ressaltado e a resiliência refere-se às significações apresentadas pela pessoa como um processo e não como um conjunto de atributos do indivíduo comparado a outros indivíduos. Sobre a compreensão de resiliência no presente estudo, tratamos a seguir.

\section{Resiliência na perspectiva bioecológica}

Tomando por base a perspectiva bioecológica, é possível entender melhor os processos dinâmicos de interação entre os diferentes níveis de desenvolvimento, influenciados pela interação da pessoa com o meio e sua capacidade de descobrir, sustentar ou alterar suas propriedades, bem como suas percepções encontradas diante da situação de risco. (Infante, 2005; Garcia; Yunes, 2006)

A compreensão do conceito, a partir desse ponto de vista, leva à observação da inter-relação dos aspectos individuais com os ambientais, permitindo a superação de uma visão de resiliência que enfatiza as características individuais e classificatórias dos indivíduos em "resilientes ou não resilientes", para pensá-la pela via do contexto, seja familiar, seja do mundo social.

Para Yunes (2001), a amplitude do modelo bioecológico de desenvolvimento e a ênfase colocada na complexidade e poder das interações entre organismoambiente são consideradas ideais para auxiliar na compreensão das questões referentes a risco, proteção e resiliência.

Na condição de processo, a resiliência implica uma rede de fenômenos 
articulados entre si estruturada ao longo da vida e em diferentes contextos (cultural, afetivo, social). Nesta perspectiva, o ambiente e seus componentes fazem parte do fenômeno em processo e compreendem a relação entre o contexto e as características da pessoa em desenvolvimento.

Risco e proteção são processos que constituem a resiliência. Cecconello (2003, p. 25) afirma que "resiliência se refere a comportamentos adaptados em resposta a fatores de risco" e, diante desta ideia, procura-se entender primeiramente os fatores de risco, uma vez que estes, na visão de Poletto e Koller (2008, p. 31), “estão relacionados a toda sorte de eventos negativos de vida que, quando presentes no seu contexto, aumentam a probabilidade de o indivíduo apresentar problemas físicos, psicológicos e sociais".

De acordo com Costa e Assis (2006), o risco não pode ser visto como uma categoria a priori, mas como um processo, ou seja, não se pode atribuir como risco uma determinada situação sem entender os mecanismos que influenciam o risco e o ligam às suas consequências. A resiliência, por sua vez, refere-se a processos que não eliminam o risco, mas operam na presença deste, ou ainda, encorajam o indivíduo a engajar-se efetivamente na situação e sair dela fortalecido.

Mesmo a resiliência estando atrelada à presença de uma condição adversa, é preciso considerar que, no contexto no qual os indivíduos estão inseridos e desenvolvem-se, podem ser encontrados outros fatores que podem agir como agentes protetivos, que acabam por atenuar os efeitos nocivos do risco e promover a construção da resiliência. (Benetti; Crepaldi, 2012)

Os fatores de proteção, por sua vez, têm a função de interagir com os eventos estressores da vida e acionar processos que possibilitem melhorar a adaptação e a saúde emocional (Poletto; Koller, 2008). Eles explicam como diferentes indivíduos, submetidos às mesmas condições adversas, alcançam resultados desenvolvimentais diferentes. É na presença do risco que encontramos a ação dos fatores protetivos e estes, por sua vez, têm a função de modificar a resposta do indivíduo em situações adversas.

Na perspectiva de Poletto e Koller (2008, p. 35), a proteção não elimina o risco, mas encoraja o indivíduo a engajar-se em uma situação de risco e "o que ocorre é uma mudança na maneira como os indivíduos enfrentam as situações em suas vidas, principalmente quando submetidos a circunstâncias estressantes". Dessa forma, a condição de risco é prioritariamente um fator para se pensar em resultados resilientes, pois a resiliência surge como um comportamento adaptado em resposta a uma situação de risco vivenciada pelo sujeito.

Nesse viés de discussão, a resiliência é resultante de uma tessitura que envolve as adversidades e o processo de significação delas, o que implica reconhecer fatores de risco e de proteção presentes na produção de sentido para o que foi 
vivido pela pessoa (Ceconello, 2003). A história de vida do indivíduo, o processo de interpretação e a busca do sentido, por parte do sujeito, devem ser levados em conta nas pesquisas em resiliência para se captar a complexidade do fenômeno. (Libório; Castro; Coelho, 2006)

Portanto, na trajetória de vida, o modo como cada sujeito significa suas vivências, nos diferentes sistemas nos quais está envolvido, influencia na resiliência do indivíduo, ou seja, nas estratégias de enfrentamento diante das situações adversas. Diante de situações que enfraquecem suas possibilidades de reagir de modo a favorecer seu desenvolvimento saudável (risco), estratégias de enfrentamento podem ser construídas, apoiadas em mecanismos protetivos, constituindo resiliência e alterando o curso que o risco poderia provocar no processo evolutivo da pessoa.

\section{Procedimentos metodológicos adotados}

0 presente estudo orientou-se pelos parâmetros da pesquisa qualitativa, de cunho descritivo, na modalidade de estudo de caso (Gil, 2007; Yin, 2001). Embora não se tenha adotado em sua complexidade o paradigma da inserção ecológica, dois pressupostos principais desse modelo servem como orientação: "princípio da contextualidade" e "da ampliação das fontes de coleta de dados". (Bronfennbrenner, 1996; Libório; Castro; Coelho, 2006)

Para tanto, optou-se pela observação sistemática da SAA em uma escola da rede estadual de ensino, localizada na região oeste do Município de Londrina-PR. Além da observação, os professores (da sala de apoio e da sala regular), os alunos, os pais e as pedagogas foram entrevistados, a partir de um roteiro semiestruturado.

\section{Fatores de risco e de proteção presentes no cenário da sala de apoio -os dados do estudo}

A pesquisa contou com a participação de treze alunos e seus familiares, tendo como representantes dos familiares ${ }^{2}$ onze mães, duas avós e um pai luma mãe e uma avó representavam um mesmo aluno); três pedagogas ${ }^{3}$, duas professoras

1. Os nomes dos alunos participantes foram substituídos pela letra A seguida dos números 1, 2, 13.

2. Os nomes dos familiares participantes foram substituídos pela letra $F$ seguida dos números 1, 2,13.

3. Os nomes dos pedagogos participantes foram substituídos pelas letras PE seguidas dos números 1,2 e 3. 
da sala de apoio à aprendizagem ${ }^{4}$ luma da disciplina de matemática e outra da disciplina de língua portuguesa); cinco professores da sala regular $^{5}$ ( três da disciplina de matemática e duas da disciplina de língua portuguesal. Uma das professoras de língua portuguesa é, ao mesmo tempo, professora da SAA e da sala regular.

Procurou-se sintetizar os dados enfatizando o sentido atribuído pelos participantes $^{b}$ ao não aprender e ao trabalho na SAA. Interessa articular esses sentidos à ideia de risco e proteção nas interações que ocorrem no processo de aprendizagem no espaço da sala de apoio. Esclarece-se que, neste estudo, o risco e a proteção apontados não devem ser generalizados como equivalentes para todos os sujeitos em diferentes contextos. (Yunes, 2001)

O conjunto dos dados permite que sejam elencados vários fatores como desfavoráveis ao aprender e que, portanto, constituem risco; dos mesmos dados depreendem-se indicativos de proteção, favorecedores de resiliência no contexto da sala de apoio investigada. Risco e proteção, portanto, são compreendidos neste estudo como processos que contribuem para 0 desenvolvimento da resiliência e isso implica dizer que ela não é inata, mas pode ser promovida ao longo do ciclo vital.

É na presença do risco que encontramos a ação dos fatores protetivos, e estes, por sua vez, têm a função de modificar a resposta do indivíduo em situações adversas. Rutter (1985 apud Yunes, 2001, p. 38) esclarece que os "fatores de proteção correspondem às influências que modificam, melhoram ou alteram respostas individuais a determinados riscos de desadaptação".

Na perspectiva de Poletto e Koller (2008, p. 35), a proteção não elimina o risco, mas encoraja o indivíduo a se engajar numa situação de risco e “o que ocorre é uma mudança na maneira como os indivíduos enfrentam as situações em suas vidas, principalmente quando submetidos a circunstâncias estressantes". Dessa forma, a condição de risco é prioritariamente um fator para se pensar em resultados resilientes, pois a resiliência surge como um comportamento adaptado, em resposta a uma situação de risco vivenciada pelo sujeito. Daí a importância dos fatores de proteção e sua contribuição para o estudo da resiliência. "Os fatores de proteção têm relação com a maneira

4. Os nomes dos professores da sala de apoio participantes da pesquisa foram substituídos pelas letras PSA seguidas dos números 1 e 2.

5. Os nomes dos professores da sala regular foram substituídos pelas letras PR seguidas dos números $1,2,5$.

6. As manifestações dos participantes foram grafadas em itálico para diferenciá-las de outras citações autorais. 
como as pessoas encaram as dificuldades da vida e como dão significado às circunstâncias estressantes ou desvantajosas". (Oliveira et al., 2008, p. 764)

Dado o volume de dados e a necessidade de recorte a que somos impelidos, apresentamos os dados coletados nos grupos de participantes (professores da sala de apoio e da sala regular, pedagogos, familiares e alunos) tomando por base a identificação de fatores de risco e de proteção nos significados que dão ao não aprender.

\section{Identificando fatores de risco e proteção na SAA: significados atribuídos pelos participantes}

\section{0 que afirmaram os pedagogos em relação ao não aprender e à SAA?}

Nas respostas dos pedagogos, observamos distintas significações por meio das quais o não aprender é caracterizado: "imaturidade dos alunos", "tempo de aprendizagem", "deficiência da escola”, “formação do profissional”, " problemas familiares, sociais ou psicológico", "diferentes modos de aprender", "desinteresse do aluno", “aluno indisciplinado", “falta de conteúdos significativos”, “metodologia do professor", "falta de articulação entre os professores e equipe pedagógica" (PE1, 2 e 3).

Para apreender melhor o trabalho desenvolvido no contexto da sala de apoio, procuramos investigar também como os pedagogos percebem a SAA. Os entrevistados referem que, ao coordenar o trabalho desenvolvido, percebem que a aprendizagem dos alunos nesse espaço poderia ser mais efetiva se conseguissem acompanhar e articular melhor esse trabalho (PE1) e se os pais fossem "mais comprometidos" com o programa (PE3). Porém, ainda assim, consideram mais significativo o aprender nesse espaço, como indica PE2: "porque vai fazer a diferença esse aluno que veio aqui pra escola fora do horário, vai refletir lá na sala em todas as disciplinas".

Embora nas falas dos gestores ainda seja predominante a localização do não aprender no aluno e em sua família, surgem outros elementos na definição que apontam para o que tem sido indicado na literatura atual acerca das múltiplas faces do aprender: um fenômeno complexo que não pode ser "fatiado" e desconsiderado em seu conjunto.

É importante reconhecer que as dificuldades de aprendizagem implicam coocorrência para que o não aprender não seja determinado apenas por avaliação do desempenho escolar, aspectos cognitivos, constatações ou por alguma característica de inadequação vista de forma isolada. 


\section{0 que afirmaram os professores em relação ao não aprender e à SAA?}

Questionados sobre as razões pelas quais os alunos não aprendem, elencaram alguns fatores: "dificuldade nas operações, principalmente em divisão" (PR1, PR2), “leitura, escrita e interpretação” (PR3, PR5), “ortografia, pontuação” (PR4, PSA2) e até mesmo a "organização da segunda etapa do ensino fundamental" (PR3).

Os depoimentos indicaram as dificuldades dos alunos nos conteúdos das disciplinas de língua portuguesa e matemática que perpassam os aspectos de dificuldades de aprendizagem da linguagem, da leitura, da escrita e da matemática. Porém, há outras dimensões como a falta de incentivo, de adaptação à organização da segunda etapa do ensino fundamental e até mesmo de necessidades educativas especiais como apontou (PR3).

A análise desses depoimentos revela causas do não aprender centradas no aluno e, como alerta Patto (1999), muitas vezes as causas intraescolares do fracasso escolar e a crítica ao sistema de ensino são secundarizadas. Os professores são capazes de lançar seu olhar para o processo, mas a partir de suas respostas não podemos assegurar que se percebem como parte dele, pois não atribuem as causas do não aprender às suas práticas, concepções educacionais, crenças acerca do processo ensino-aprendizagem. Como mostra Souza (2012), muitas vezes o profissional não tem a dimensão de que o fracasso ou o sucesso no processo de aprendizagem não é determinado apenas por questões individuais do aluno.

Outra questão que nos instigou diz respeito à falta de destreza para avaliar as dificuldades de aprendizagem (laudo médico, medicalização) dos alunos que fazem parte da sala de apoio, dificuldade essa não manifestada em relação àqueles que fazem parte de outro programa. Na entrevista, os professores citam que os alunos, os quais fazem tratamento médico com outro profissional, frequentam a sala de recursos, como podemos verificar na fala de alguns dos entrevistados: “[...] os alunos que fazem algum tratamento, que toma uma certa medicação está indo pra sala de recurso, né” (PR2). [sic] “[...] Aqui só vem aluno com defasagem mesmo. Pode ser que eles estejam assim, tipo assim, procurando laudo. A mãe tá [sic] atrás do laudo, aí tá aqui primeiro pra depois ir pra lá, entendeu?" (PSA1). [sic]

Mesmo constatando que os alunos que possuem laudo não participam da SAA, observa-se que há uma justificativa da não aprendizagem também pela via da patologização, ou do adoecimento que permeia o processo de ensino e aprendizagem na escola. A questão da patologização, medicalização ou biologização do ensino é discutida por autores como Souza (2012), que enfatiza a causa para os encaminhamentos dos alunos para a área médica: o mau rendimento escolar é 
a destinação oficial para as classes especiais, como é o caso da sala de recursos indicada pelos participantes de nossa pesquisa.

Justificar o não aprender na escola pela via da patologia é um retrocesso no campo educacional e atribuir às crianças as causas do não aprender é penalizálas duplamente, sobretudo por não oferecermos uma escola de qualidade e utilizarmos tratamentos, inclusive.

Quanto à SAA, os professores entendem que, apesar das dificuldades encontradas, ela é significativa à aprendizagem do aluno. Por meio dos depoimentos dos professores, foi possível compreender os sentidos da experiência do trabalho escolar desenvolvido na SAA e observar alguns significados acerca de condições necessárias para aprender. 0 número de alunos na sala de aula é um fator relevante que denuncia as condições conjunturais. Os professores indicam também a intervenção do professor, mediante aulas mais dinâmicas, com jogos e materiais concretos.

Além disso, a maioria dos professores da sala regular relata que o aluno, quando encaminhado para a sala de apoio, não tem tempo determinado para concluir o processo. Afirmam que o tempo de permanência depende do desenvolvimento do aluno, como podemos observar nesse relato: "Olha se for um aluno que tem tudo isso que eu disse, frequência, seriedade, acho que uns três meses, dois, é difícil avaliar né, porque é de cada um, mas por aí. Uns dois, três meses". (PR2).

Para compreender o significado do não aprender na sala de apoio, buscamos ainda perceber, por meio das observações realizadas, quais critérios eram levados em conta para que o aluno fosse dispensado de sua participação no programa. Assim, procedemos por considerarmos que tanto o processo de avaliação para o encaminhamento quanto o processo avaliativo para a suspensão da indicação de participação do aluno são reveladores dos modos de lidar com esse programa na escola.

Não podemos desconsiderar que, toda vez que esses elementos aparecem de modo integrado (contexto, processo, pessoa e tempo), há que se considerar a coocorrência. Dessa forma, no intuito de compreender como é o processo que rege a SAA, questionamos os entrevistados quanto à saída do aluno desse espaço.

Os entrevistados indicaram critérios diversificados, tais como: "avalia como tá o desempenho dele" (PR2), "ele tem acho que corresponder né, porque se não tiver evolução não tem necessidade de cortar né" (PR3), “ah, eu acredito que ele tenha avanços né (PR5), “essa superação da dificuldade (PSA1), “então, assim, a nota lá na sala regular né, se a nota estiver bem" (PR4, PSA2).

Observa-se ênfase no conteúdo, no rendimento expresso em nota. Nessa discussão acerca dos processos, aparece uma relação de falta de continuidade entre uma aprendizagem e outra. Quando o aluno no ensino médio não consegue 
compreender os conteúdos específicos e o professor detecta que esse problema é anterior ao conteúdo que foi apresentado porque tem a ver com noções básicas (como, por exemplo, a questão da tabuada), há uma indicação de que um processo faltoso ocorreu.

Este processo, indicado como lacunar pelos professores, acompanha a trajetória de escolarização do aluno ao longo dos anos. A identificação das dificuldades de aprendizagem e, consequentemente, os encaminhamentos dados perdem consistência na sua reparação por parte da escola. Partindo de diagnósticos aligeirados, este processo faz com que as dificuldades de aprendizagem continuem sendo vistas, na maioria dos casos, como um problema localizado no aluno, ignorando sua produção no cotidiano escolar e outros aspectos que o influenciam.

Não há consenso entre os entrevistados sobre quem toma a decisão de saída do aluno da SAA, que deveria respeitar o progresso no processo de aprendizagem com avaliação específica, indicando essa trajetória de crescimento, de evolução. Uma avaliação processual, portanto. Porém, os professores estão indicando, por meio de suas falas, que a avaliação do processo é desrespeitada para atender a outras demandas, tais como aumentar o número de alunos atendidos pela escola no programa e, portanto, não manter por longo tempo o mesmo aluno na SAA; ou, ainda, a consideração apenas da nota da prova para a suspensão do acompanhamento do aluno na SAA no meio do bimestre, tendo em vista que alcançara a nota mínima requerida.

A "ficha avaliativa", documento oficial de avaliação do desempenho do aluno na sala de apoio, que deveria revelar o acompanhamento da evolução da aprendizagem, passa a ser um instrumento de classificação, a indicar se o aluno está dentro ou fora dos "parâmetros comportamentais" aceitos pelo professor nesse espaço. Ao valer-se da ficha com esta estratégia, "o professor transmite a mensagem de que a única opção para o aluno é submeter-se, ou poderá sofrer as consequências". (Galvão, 2013, p. 36). A forma de lidar com este instrumento de avaliação não está de acordo com o que é proposto pelo programa. A ausência de ações integradas no programa alerta para o fato de que o processo pode ser comprometido. Por ser comprometido, esse processo fica impedido de acontecer e não ocorre um registro fidedigno da evolução dos alunos. Ele continua centrado nos resultados e isso justifica o uso da ficha como elemento intimidador, de controle. Alves (2007, p. 169) nos alerta: "o problema que resulta de se pensar o ensino a partir da busca de resultados [...] é que as decisões e práticas educativas, intrinsecamente ligadas a valores humanos e eminentemente políticos, são reduzidas a decisões técnicas".

Nas observações e no registro das fichas a que tivemos acesso, foi possível notar que elas são preenchidas como se o professor estivesse tratando de um único aluno. Elas são compostas de frases padronizadas que se repetem para 
todos os frequentadores da SAA.

Nesse sentido, o processo se perde completamente, pois, a partir do momento em que se apresenta fragmentado, está impedindo a relação interdependente dos elementos que compõe o sistema. Esse modo de avaliar é tomado como um produto, sem que o processo que o originou seja considerado; “interessa ao professor/examinador apenas a demonstração da retenção das informações, independentemente do nível compreendido ou apropriado". (Galvão, 2013, p. 36)

\section{0 que afirmaram as famílias acerca do não aprender e da SAA?}

Alguns fatores também apresentados pelos professores apareceram nas respostas dadas pelas famílias, dentre eles: "descompromisso do professor com o ensino" (F1), "influências de más amizades” (F2), "falta de interesse, de atenção ou preguiça por parte do aluno" (F8, 9, 10 e 11), "dificuldades de aprendizagem" (F4, 5 e 13), "problemas familiares" (F6, 7 e 12).

Interessante observar a fala do membro de uma das famílias (F7) que não apenas percebeu os elementos que constituem o sistema, como também se percebeu parte dele, afirmando que a falta de acompanhamento dos pais pode ser um indicador das dificuldades apresentadas pelo filho. Dessa forma, nas questões que envolvem o não aprender, tanto as razões internas como externas à família desfavorecem a aprendizagem.

Os dados coletados junto às famílias apontam a complexidade e dinamicidade do processo de ensinar e aprender e enumeram vários aspectos que caracterizam as dificuldades de aprendizagem escolar, como evidenciam os estudos de Garcia (1998) e Yaegashi (2012), além de indicarem a percepção de sua implicação no processo de aprendizagem dos filhos.

Na proposta de Bronfenbrenner (1996), as famílias que oferecem às crianças atividades organizadas em que elas podem se engajar facilitam seus processos de desenvolvimento.

A família também foi convidada a indicar se a participação do filho na SAA trouxe alguma mudança para a aprendizagem. Em alguns depoimentos, não são percebidas mudanças significativas: “Ah, eu não achei que teve mudança não, ele continua do mesmo jeito, ele não coloca as coisas na cabeça, ensina, ensina, só entra na hora depois passa" (F2). Em outros, a família encontra significado neste trabalho. Observamos que há aspectos secundários que entrecortam o processo de aprendizagem e são estes que se evidenciam. 0 depoimento de F5 indica que o aluno obteve alguns ganhos como, por exemplo, o filho deixar de ser uma criança retraída e passar se comunicar melhor, embora, com relação ao aprendizado, não 
houvesse ganho significativo. A fala de F7 revela outra dimensão. 0 significado para essa mãe, de a filha ir bem na sala de apoio, é não repetir sua trajetória de vida, subemprego, condições precárias de trabalho por não ter estudado. Há um sentido muito importante para essa família, que é a oportunidade que a escola confere de ter um bom emprego, representando possibilidade de superação da condição de vida pela próxima geração por meio de melhores condições financeiras.

Apesar de os aspectos secundários que entrecortam o processo de aprendizagem não serem correspondentes àqueles pelos quais os alunos devem se manter na SAA, esta relação pode ser considerada positiva ou protetiva na medida em que favorece a vinculação com a escola.

Como alerta Lahire (1997), a apropriação de um “capital cultural” não é impossível para quem não o possui em seu ambiente familiar, e, com este dado, queremos mostrar que esses significados são legítimos a essa comunidade, apesar de estarem distantes da importância de significar o ensinar e aprender nessa via. A família apresenta sua forma de investimento para atingir o sucesso escolar embora seja diferente daquilo que a escola espera, havendo um confronto dessas expectativas.

Emsetratando da relação entreesses dois microssistemas, o que o microssistema familiar e o microssistema escolar compreendem acerca do ensinar e do aprender é muito distinto. Por isso, conforme aponta Silva (2007): parece ser mais frutífero, na análise da relação família-escola, explorar o campo da significação da escola para alunos e famílias, analisando o cotidiano familiar, do que atribuir o fracasso à carência cultural, à ideologia do dom e às deficiências na organização familiar. Os dois microssistemas reconhecem a importância de frequentar a sala de apoio, mas as expectativas são diferentes. Embora, no resultado, pais e escola estejam querendo que o aluno permaneça na SAA, as razões que mantém o aluno, tanto para o encaminhamento quanto para o acompanhamento desse aluno, são muito distintas, para a família e para a escola.

Entretanto, por outro lado, existem alguns momentos em que há uma correspondência mais aproximada entre a expectativa da escola e a expectativa da família, como, por exemplo, quando algumas famílias revelam que houve mudanças em relação ao "interesse, atenção" (F8), "a criança se encontra mais focada nos livros" (F9), "ficou mais adiantada nos estudos" (F10), "evoluiu bem" (F13). Outras mudanças foram relevantes como podemos observar em alguns relatos: "oh, ele teve uma mudança sim porque a gente pergunta, faz continha de cabeça, ele já tá acompanhando então" (F3).

Diante destas declarações, não podemos desconsiderar que a sala de apoio tem contribuído para o desenvolvimento e aprendizagem dos alunos, mas, diante do sentido dado, é preciso aproximar mais as expectativas em relação a esse 
programa, analisando e estudando os processos que estão ali envolvidos. É este o ponto de maior lacuna encontrado nos dados, uma vez que o processo é o maior indicador da presença ou ausência da articulação entre os elementos envolvidos.

Integrando esses elementos do processo, é importante destacar ainda o modo como a família se insere e se percebe nesse espaço da sala de apoio. Descobrir as estratégias que as famílias encontram para acompanhar a trajetória do aluno na escola e na SAA amplia nossa compreensão sobre qual é o lugar que a família ocupa no processo de ensinar e aprender.

Revelar as formas de acompanhamento dos filhos contribui para retificar a interpretação corrente no contexto escolar de que há omissão dos pais em relação à vida escolar de seus filhos. Como esclarece Lahire (1997), “omissão parental é um mito". Nas palavras do autor, "esse mito é produzido pelos professores, que, ignorando as lógicas das configurações familiares, deduzem, a partir dos comportamentos e desempenhos escolares dos alunos, que os pais não se incomodam com os filhos". (Lahire, 1997, p. 334)

Por meio da entrevista realizada, verificamos que as famílias procuram acompanhar a vida escolar dos filhos por meio de telefonemas (F1. F8), reuniões (F8, F9), observação dos cadernos e tarefas do aluno (F3 e F11), por meio de vizinhos e colegas (F10, F12) além de comparecer à escola quando solicitadas (F2, F7) ou, às vezes, comparecer mesmo não sendo chamadas (F13).

Os dados apontados aqui tornam visível a postura familiar que não está alheia ao que acontece na escola, e, como explica Caetano (2012), cabe aos profissionais em educação investir numa relação de parceria com a família com vista à formação autônoma da criança. "Não podemos, como professores, manter os mesmos discursos abusivos e, [...] equivocados de que a família não sabe educar". (Caetano, 2012, p. 38)

Notamos que há diferentes formas do envolvimento da família e todas são legítimas porque têm a ver com a realidade de cada uma, com o modo como elas estão estruturadas e com o sentido que a aprendizagem do filho ocupa naquele espaço.

Falar da participação da família implica reconhecer suas múltiplas formas de envolvimento possíveis na trajetória escolar dos alunos. Em uma abordagem sistêmica, como a que adotamos, podemos afirmar que essas famílias são envolvidas. Estamos evidenciando um significado que a sala de apoio tem para cada família, significados legítimos, independentemente de serem correspondentes ou não aos objetivos da SAA.

Por outro lado, a partir dos relatos apresentados, ressalvamos que, no sentido atribuído pela escola e pela família, a culpa pelo não aprender recai sobre o aluno, já que a família está cumprindo o seu papel de fiscalizar e a escola o de ensinar, 
então o aluno é quem está deixando de "ser sério".

A mesma ocorrência se atrela à permanência do aluno na sala de apoio, pois, para que ele permaneça neste espaço, outros princípios que não o aprender, tomam lugar: ou é pelo princípio da autoridade, seja da família, seja da escola, em razão da necessidade de controle; ou serve como um regulador das atividades do aluno enquanto os pais trabalham. Dessa forma, as razões para a manutenção do aluno na sala de apoio nem sempre têm foco na aprendizagem, quer para a família, quer para o aluno, quer para a escola. Garantir a permanência das crianças na escola não tem sido suficiente porque não estamos garantindo um bom desempenho. (Bahia, 2012)

Ao atribuirmos ao aluno a responsabilidade pelo não aprender, retiramos outras possibilidades de análise, como, por exemplo, as condições objetivas do trabalho do professor, ausência de formação para a realização deste trabalho, a constituição e funcionamento da SAA, formas de encaminhamento, ou as atividades trabalhadas de forma "infantilizadas", entre outras.

Os significados sustentam as concepções e práticas que os participantes adotam na sala de apoio e é por essa razão que relacionamos esses fatores a risco e proteção. Não basta que o programa seja constituído para oportunizar apoio à aprendizagem, é preciso "olharmos" para ele funcionando para depreendermos mecanismos protetivos e de risco nesse processo.

\section{0 que afirmaram os alunos em relação ao não aprender e à SAA?}

Ao atribuírem sentido às próprias dificuldades para aprender, os alunos localizam áreas do conhecimento e depois localizam conteúdos específicos nestas áreas. Este dado revela que possuem clareza quanto ao que é esperado deles em termos de demandas e ao que de fato têm conseguido realizar.

As disciplinas citadas por eles como aquelas com que têm dificuldades foram: matemática, língua portuguesa, inglês, geografia, ciências, história. Com relação aos conteúdos citados dentro das disciplinas que são eleitas no programa da sala de apoio, ou seja, língua portuguesa e matemática, algumas dificuldades foram destacadas: "continha de dividir" (A12), "[...] fazer aquelas perguntas do texto. Eu não leio (risos) só leio quando a professora manda" (A11), “[...] Em português... ah, é mais nas perguntas, meio que tem, que você tem que ler um texto, aí depois a professora passa aquelas perguntas bem difícil, [...] matemática... continha de dividir, que tem tipo três números (a9); matemática [...] Então, assim, as matérias mais avançadas que eu ainda não consegui entender. Não consigo entender. [...] Em português é que as vezes eu troco as letras (A7). 
Podemos compreender outros aspectos sobre o processo que está em andamento na SAA nesta unidade escolar quando os alunos manifestam como se percebem nesse processo de escolha e seleção para fazerem parte da SAA.

Entre os alunos entrevistados, apenas dois deles disseram que não sabiam por que tinham sido escolhidos (A1 e A4). Somente uma aluna (A11) disse que foi para a SAA porque conversava muito. Questionada se não tinha nenhuma dificuldade, ela disse que não, que suas notas eram boas e que apenas uma era vermelha: em matemática. Quando questionada por que tinha essa nota vermelha, ela respondeu: "A professora andava faltando muito e agora veio o professor, bem no finalzinho do ano" (A11).

Ao trazermos esses depoimentos para nossa análise, estamos enfatizando, conforme Yunes (2001), a importância de reconhecer a percepção que o sujeito tem da situação em que se encontra. Ao ouvir e dar voz ao sujeito, evidencia-se a importância da experiência e percepção do indivíduo sobre as situações vividas em seu ambiente, bem como nas peculiaridades das experiências vivenciadas pelo sujeito num contexto específico. (Polettto e Koller, 2006; Morais, 2009)

A2 e A13 explicam que foram para a SAA porque suas notas eram ruins. Os demais alunos percebem sua dificuldade e se declaram como "ruim na matéria" $(A 3, A 5, A 6, A 7, A 8, A 9, A 10, A 12)$ como indicam os relatos: "Porque eu tô [sic] muito ruim em matemática. [...] Conta de dividir, nossa, aí aperta" (A8).

No trabalho que envolve a SAA, há alguns desencontros que talvez se relacionem aos fatores que já discutimos (por exemplo, a organização, funcionamento e plano de trabalho da sala de apoio). 0 processo de seleção dos alunos não é claro, pois se percebe no modo como os alunos significam esse espaço que alguns identificam suas dificuldades e que outros não sabem o porquê de sua participação nesse programa. Verificamos que o problema de indisciplina também perpassa esse processo.

A participação do aluno na SAA, mesmo que compreendida por vias não muito adequadas no que se refere ao processo de ensino e aprendizagem, é indicada pelos alunos como contribuindo de alguma forma para seu desenvolvimento, como indicou A10.

Da mesma forma, os critérios de saída não ficam claros também na percepção dos alunos. A fala de um dos alunos entrevistados revela o motivo pelo qual não está mais participando da sala de apoio: “Porque a professora me tirou. É que duas aulas eu não fiz, eu não sabia, aí ela me tirou, eu não fazia as coisas mais. Ela falou que não precisava mais vir" (A6).

Sendo assim, qual o significado do aprender e do não aprender no espaço da SAA? Quando o foco não está no processo de ensino e aprendizagem, outros aspectos tomam lugar: estigmas, preconceitos, exclusão, ou outros problemas localizados 
no aluno (Goffman, 1988; Patto, 1999; Collares; Moysés, 1996, Bahia, 2012). Se o aluno aprende ou não, passa a ser por razões que tangenciam a aprendizagem, mas não a consideram em sua essência. Tomando Aquino (1997) por base, essa situação aponta um efeito colateral e se alastra na figura do "aluno-problema".

Todos os elementos que compõem especificamente a questão precisam ser analisados, pois, ainda que não tenhamos clareza, o processo mantém uma relação de codependência entre os elementos que o compõem. No entanto, ele aparece entrecortado, quando família tem uma expectativa, como a mãe que quer poder dormir e descansar do trabalho, bem como a escola de atender ao núcleo ou a secretaria de educação, e o aluno porque não gosta de ficar em casa. As questões de aprendizagem não ficam com o lugar de destaque.

Os alunos também indicam que a sala de apoio os ajuda a compreenderem melhor os conteúdos de Língua Portuguesa e Matemática (A3, A4, A5, A8, A9, A10, $A 11, A 12, A 13)$ e alguns justificam como a sala de apoio ajuda: "Ah, nas contas né, antes eu não fazia bem agora eu to acertando já fazer" (A3) É... quando nois faiz alguma coisa sobre verbo, daí eu já sei" (A4); "Produção de texto. Eu to [sic] indo bem em produção de texto (A5); “Porque quando eu cheguei aqui eu tava [sic] com muita dificuldade, agora que eu tô [sic] vindo pra sala de apoio, eu tô [sic] aprendendo mais, por isso" (A10).

Três dos alunos (A1, A2, A7) acham que a sala de apoio ajuda "mais ou menos" em sua aprendizagem e argumentam: "Eu fico no português porque eu tenho que ficar na escola..., ah sei lá, mas aquela lá, ela passa conteúdo da quinta série e eu tô [sic] no sétimo ano daí" (A1); "Bom, porque as matérias, as perguntas que ela passa eu aprendi no ano passado. Ai tô [sic] vendo algumas matérias que eu to aprendendo esse ano. Tem algumas pergunta que já é desse ano já". (A2).

Entretanto, todos os alunos participantes da pesquisa consideraram ser mais fácil aprender na sala de apoio e revelaram vários motivos que consideramos importante elencar. Trata-se de problemas como: a "indisciplina dos alunos na sala regular," "compreensão do conteúdo" e "metodologia do professor". Assim, a sala de apoio é apresentada pelos participantes como produtora de risco e de proteção, confirmando o que discutimos do ponto de vista teórico neste estudo quanto à resiliência ser constituída pelo movimento entre fatores de risco e de proteção em um dado contexto. Nossos dados indicam a necessidade de que as políticas públicas educacionais responsáveis por programas como este incorporem em suas análises tais elementos, oriundos das vozes dos protagonistas, que atuam neste cenário, a fim de aprimorar o alcance dos objetivos dos programa de apoio à aprendizagem escolar. 


\section{Considerações finais}

A visão do não aprender, evidenciada nesse estudo, demonstra que, da maneira como a sala de apoio é pensada e/ou compreendida, as causas do não aprender acham-se centralizadas no aluno, ignorando outros fatores do contexto escolar que contribuem com as dificuldades de aprendizagem. 0 não aprender representa mais do que uma resposta insuficiente do aluno às demandas da escola. Representa a complexidade de um processo que passa pelas significações atribuídas pelo sujeito à não aprendizagem.

A compreensão da sala de apoio à aprendizagem nos permitiu reconhecer risco diante do qual os fatores protetivos podem manifestar-se, dependendo das significações dadas ao processo desenvolvido. Assim, a pesquisa pautou-se pelo princípio de que a resiliência manifesta-se diante dessas situações desafiadoras ou de risco. Deste modo procuramos sintetizar nossos dados enfatizando o sentido atribuído pelos participantes ao não aprender e ao trabalho na SAA. Esclarecemos que o risco e proteção apontados aqui não devem ser generalizados como equivalentes para todos os sujeitos em diferentes contextos.

0 que pode ser considerado risco é a incompreensão acerca de quais processos são pertinentes à SAA. É preocupante a visão biologizante do aprender, que ainda é predominante, e, mais especificamente, é preocupante o fato de a patologização e medicalização poderem ser cotejadas com a resiliência. A medicação, suposta proteção aos sujeitos da aprendizagem, em relação ao risco - não aprender -, acaba por tornar-se ela mesma o risco que afasta ainda mais as possibilidades da pessoa em desenvolvimento, pois a prejudica em seu funcionamento orgânico, promovendo entre outros sintomas, a apatia e a desorganização mental. Mas para além desse fator, segrega, rotula e diferencia. A patologização do aprender cumpre o papel de ratificar que as dificuldades de aprendizagem se localizam no sujeito e em sua incompetência interna, em suas famílias "desestruturadas" e pouco interessadas pela aprendizagem, ou ainda na comunidade à qual estes alunos se vinculam.

Fatores de risco, cristalizados e revestidos por nova roupagem, conforme avança a história, são, entretanto, impedidores da relação destes alunos com 0 saber especializado da escola, obstaculizadores da construção de estratégias de enfrentamento - resiliência - aos riscos próprios à condição que essa situação agrega.

Por outro lado, é preciso reconhecer, na busca por articular os sentidos do não aprender produzidos neste espaço, que este contexto - a SAA - é relevante ao aluno. Um espaço que oportuniza o atendimento mais direcionado, maior monitoramento das condições do aluno no processo, possibilita intervenção mais próxima por 
parte do professor naquilo de que o aluno necessita em seu aprendizado.

Outro elemento de composição de risco, em nosso entendimento, é relativo ao processo de saída do aluno da SAA, quando não há um consenso sobre quem toma a decisão, o que revela falta de acompanhamento do processo. Os entrevistados indicaram critérios diversificados e, na maioria das vezes, a decisão para a definição do momento de saída do aluno não é conjunta. Nesse aspecto, se soma, na produção de risco à aprendizagem dos alunos, a visão do professor acerca do não aprender e da sala de apoio que, sendo vista como espaço de superação das dificuldades, assume um lugar messiânico e, portanto, polariza por um lado o aluno e por outro a escola (SAA), e o processo novamente é ignorado.

Entretanto, mesmo nessa situação, é possível identificar como fator de proteção o fato de a maioria dos professores da sala regular relatar que o aluno, quando encaminhado para a sala de apoio, não tem tempo determinado para concluir o processo. Afirmam depender do desenvolvimento do aluno, e isso nos remete a uma sensação de que o processo de aprendizagem de cada aluno vai ser considerado. Risco e proteção estão interagindo na mesma situação.

As fichas avaliativas também constituem risco no modo como estão sendo usadas na avaliação. Nelas é referido aquilo que falta ao aluno em relação à expectativa inicial da escola, dos professores, das famílias; entretanto, deixam de revelar o que, na condição de instrumento de registro, permitiria o acompanhamento de um processo em andamento e em contínua modificação. A avaliação fica assim reduzida à nota atribuída, que geralmente é mínima para permitir apenas que o aluno passe de ano, deixe de frequentar a sala de apoio, liberando seu lugar a outro aluno, ou ainda permitindo que o aluno seja aprovado por conselho de classe, pois passou pela sala de apoio.

As atividades propostas muitas vezes permitem ausência de identidade no trabalho ali desenvolvido, as expectativas que não convergem entre o esperado (que recuperem conteúdos dos anos iniciais do Ensino Fundamental) e a avaliação (conteúdos trabalhados, nas séries em curso). Assim, o espaço oficializado para o trabalho com as disciplinas específicas (Língua Portuguesa e Matemática) fica permeado por questões de outra ordem, na convergência de um sentido profuso de inadaptações.

Por outro lado, a SAA adquire sentido positivo pelos alunos que indicam que ela os ajuda a compreenderem melhor os conteúdos de Língua Portuguesa e Matemática. Assim, o espaço da sala de apoio tem funcionado protetivamente, pois todos os alunos participantes da pesquisa consideram ser mais fácil aprender na sala de apoio, elencando vários fatores que contribuem para esta proteção. Por exemplo, o fato de a professora explicar mais e por mais tempo determinado conteúdo gera fatores protetivos na sala de apoio, pois permite ao aluno aprender, 
diferentemente do que ocorre na sala de aula regular. Quando sabemos o que é valorizado em determinado contexto, podemos avaliar os indicadores de proteção.

Torna-se proteção quando a família também encontra significado no trabalho da SAA, o que se revela no envolvimento com a escola e com a SAA. Mesmo não sendo estas as formas de participação esperadas pela escola, todas são legítimas porque têm a ver com a realidade de cada família, com o modo como elas estão estruturadas e com o sentido que a aprendizagem do filho ocupa naquele espaço, o que pode ser entendido como resiliência porque revela a capacidade do indivíduo de criar soluções onde aparentemente não existem. 0 acompanhamento dos pais daquilo que ocorre na SAA nem sempre se efetiva de acordo com o esperado ou desejado por eles mesmos, pela escola e pelo aluno. Entretanto, manifestam interesse, buscam conversar com o aluno para saber o que eles estão fazendo na escola, saber o que está sendo organizado nesse espaço, e isso é um fator protetivo.

Despontam entre os fatores de risco, a anulação ou a pouca referência à dimensão pedagógica na sala de apoio, em nome de alguns arranjos da vida doméstica, em nome da condição de ter um "descanso" e de "ter algo a fazer para não ficar brigando" no caso das crianças que têm a oportunidade de ficar o dia todo na escola, fazer outras atividades recreativas e almoçar.

No entanto, mesmo numa situação entendida como risco, há um aspecto na promoção do processo da resiliência a ser considerado, uma vez que a participação do aluno, ainda que compreendida por vias não muito adequadas, no que se refere ao processo de ensino e aprendizagem, parece favorecer seu desenvolvimento e aprendizagem. 0 modo como os participantes lidam com as situações adversas, ainda que não modifique os resultados acadêmicos em termos de nota, indica processos de resiliência.

Observamos que existem as questões que são orientadoras, as atividades sugeridas, o espaço, as fichas de acompanhamento, a avaliação diagnóstica, mas o processo que deveria "costurar" esses elementos entre si não revela expectativas comuns. Quando pensamos no conjunto de expectativas da família, da escola e do aluno, deparamo-nos com caminhos contraditórios, ou, se não contraditórios, que não se alinham.

Esse sistema de interação constitui a rede social. Para que o sujeito obtenha sucesso na escola, é imprescindível uma rede de apoio. Apesar de as expectativas serem distintas, a significação da família e da escola converge para a permanência do programa, para a participação do aluno, o que implica reconhecer funcionamento protetivo neste contexto.

A continuidade na investigação dessa relação entre os sentidos atribuídos ao aprender/não aprender, programas de apoio à aprendizagem escolar e a resiliência 
se faz necessária, pois pode permitir compreensão não alcançada no presente estudo, como, por exemplo, apontar para os modos de lidar com o não aprender neste contexto, indo para além dos modos de perceber os sentidos atribuídos ao não aprender.

\section{Referências}

ALVES, Wanderson Ferreira. Quando ensinar não é o mais importante: reflexões sobre o trabalho docente e o ofício do aluno no contexto atual. Olhar de professor, Ponta Grossa, v. 10, n. 1, pp. 159-178, 2007,. Disponível em: <http://www.redalyc. org/articulo.oa?id=68410109>. Acesso em: 8 ago. 2013.

ANTONI, Clarissa; BARONE, Luciana Rodriguez; KOLLER, Silvia H. Violência e pobreza: um estudo sobre vulnerabilidade e resiliência familiar. In:

Resiliência e psicologia positiva: interfaces do risco à proteção. São Paulo: Casa do Psicólogo, 2006. pp. 141-171.

AQUINO, Julio Groppa. 0 mal-estar na escola contemporânea: erro e fracasso em questão. In: AQUINO, Julio Groppa. Erro e fracasso na escola - alternativas teóricas e práticas. 2. ed. São Paulo: Summus, 1997. pp. 91-109.

BAHIA, Norinês Panicacci. O fracasso escolar e a reclusão dos excluídos. São Paulo: Alexa Cultural, 2012.

BENETTI, Idonézia Collodel; CREPALDI, Maria Aparecida. Resiliência revisitada: uma abordagem reflexiva para principiantes no assunto. Revista Electrónica de Investigación y Docencia, Florianópolis, v. 7, pp. 7-30, 2012. Disponível em: <http:// www.ujaen.es/revista/reid/num7.html>. Acesso em: 22 fev. 2013.

BOROWSKY, Fabiana. Representação do self em pré-adolescentes em situação de risco: método de autofotografia. 2008. 76f. Dissertação (Mestrado em Psicologia) - Universidade Federal do Rio Grande do Sul, Porto Alegre, 2008. Disponível em: <http://www.msmidia.com/ceprua/rep_self.pdf>. Acesso em: 26 mar. 2013.

BRITO, Raquel Cardoso. Uso de drogas entre meninos e meninas em situação de rua: subsídios para uma intervenção comunitária. 1999. 129f. Dissertação (Mestrado em Psicologial - Universidade Federal do Rio Grande do Sul, Porto Alegre, 1999. Disponível em: <http://www.lume.ufrgs.br/bitstream/handle/10183/26508/ 000241287.pdf?sequence=1>. Acesso em: 26 mar. 2013.

BRONFENBRENNER, Urie. A ecologia do desenvolvimento humano: experimentos naturais e planejados. Porto Alegre: Artes Médicas, 1996.

BRONFENBRENNER, Urie. Bioecologia do desenvolvimento humano: tornando seres humanos mais humanos. Porto Alegre: Artmed, 2011.

CAETANO, Luciana Maria. Concepções educativas de pais e professores sobre o 
respeito: o sentimento de obrigação moral. In: CAETANO, Luciana Maria. (Org.). A escola contemporânea e os novos desafios aos educadores. São Paulo: Paulinas, 2012. pp.13-42.

CASSOL, Luciana; ANTONI, Clarissa. Família e abrigo como rede social de apoio social e afetiva. In: DELL'AGLIO, Débora; KOLLER, Silvia Helena; YUNES, Maria Angela Mattar. (Org.). Resiliência e psicologia positiva: interfaces do risco à proteção. São Paulo: Casa do Psicólogo, 2006. pp. 173-202.

CECCONELLO, Alessandra Marques. Resiliência e vulnerabilidade em famílias em situação de risco. 2003. 320f. Tese (Doutorado em psicologia) - Universidade Federal do Rio Grande do Sul, Porto Alegre, 2003. Disponível em: <http://www. msmidia.com/ceprua/artigos/alessandra_tese.pdf>. Acesso em: 11 mar. 2013.

CECCONELLO, Alessandra Marques; KOLLER, Silvia Helena. Competência social e empatia: um estudo sobre resiliência com crianças em situação de pobreza. Estudos de Psicologia, Natal, v. 5, n. 1, pp. 71-93, 2000. Disponível em: <http://www. scielo.br/pdf/epsic/v5n1/a05v05n1.pdf>. Acesso em: 26 mar. 2013.

COSTA, Cláudia Regina Brandão Sampaio Fernandes; ASSIS, Simone Gonçalves. Fatores protetivos a adolescentes em conflito com a lei no contexto socioeducativo. Psicologia e Sociedade, Belo Horizonte, v.18, n. 3, pp. 74-81, 2006. Disponível em: <http://www.scielo.br/pdf/psoc/v18n3/a11v18n3.pdf>. Acesso em: 4 abr. 2013.

DINIZ, Eva; KOLLER, Silvia Helena. 0 afeto como um processo de desenvolvimento ecológico. Educar, Curitiba, v. 1, n. 36, pp. 65-76, 2010. Disponível em: <http://www. scielo.br/pdf/er/n36/a06n36.pdf>. Acesso em: 15 fev. 2013.

GALVÃO, Elaine Cristina. O compromisso formativo na avaliação da aprendizagem em química: das concepções às abordagens do erro. 2013. 113f. Dissertação (Mestrado em educação) - Universidade Estadual de Londrina, Londrina, 2013.

GARCIA, Narjara Mendes; YUNES, Maria Angela Mattar. Resiliência familiar: baixa renda e monoparentalidade. In: DELL'AGLIO, Débora; KOLLER, Silvia Helena; YUNES, Maria Angela Mattar. (Org.). Resiliência e psicologia positiva: interfaces do risco à proteção. São Paulo: Casa do Psicólogo, 2006. pp.117-140.

GIL, Antônio Carlos. Como elaborar projetos de pesquisa. 4. ed. São Paulo: Atlas, 2007.

INFANTE, Francisca. A resiliência como processo: uma revisão da literatura recente. In: MELILLO, Aldo; OJEDA, Élbio Néstor Suárez. (Org.). Resiliência: descobrindo as próprias fortalezas. Porto Alegre: Artmed, 2005. pp. 23-38.

LAHIRE, Bernard. Sucesso escolar nos meios populares: as razões do improvável. São Paulo: Ática, 1997.

LIBÓRIO, Renata Maria Coimbra; CASTRO, Bernardo Monteiro; COÊLHO, Angela Elizabeth Lapa. Desafios metodológicos para a pesquisa em resiliência: conceitos e reflexões críticas. In: DELL'AGLIO, Débora; KOLLER, Silvia Helena; YUNES, 
Maria Angela Mattar (Org.). Resiliência e psicologia positiva: interfaces do risco à proteção. São Paulo: Casa do Psicólogo, 2006. pp. 89-112.

NARVAZ, Martha Giudice; KOLLER, Silvia Helena. 0 modelo bioecológico do desenvolvimento humano. In: KOLLER, Silvia Helena (Org.). Ecologia do desenvolvimento humano. São Paulo: Casa do Psicólogo, 2004. pp. 51-65.

OLIVEIRA, Marileide A.; REIS, Verônica Lima; ZANELATO, Luciana Silva; NEME, Carmem Maria Bueno. Resiliência: análise das publicações no período de 2000 a 2006. Psicologia: Ciência e Profissão, v. 4, n. 28, pp. 754-767, 2008. Disponível em: <http://www.scielo.br/pdf/pcp/v28n4/v28n4a08.pdf>. Acesso em: 18 fev. 2013.

PARANÁ. Secretaria do Estado da Educação. Instrução n0 007/2011 - SUED/SEED. 2011. Critérios para a abertura da demanda de horas-aula, do suprimento e das atribuições dos profissionais das Salas de Apoio à Aprendizagem do Ensino Fundamental, da Rede Pública Estadual de Educação. Disponível em: <http://www. educacao.pr.gov.br/arquivos/File/instrucoes/instrucao0072011.pdf>. Acesso em: 26 jun. 2012.

PATTO, Maria Helena Souza. A produção do fracasso escolar: histórias de submissão e rebeldia. São Paulo: Casa do Psicólogo, 1999.

POLETTO, Michele; KOLLER, Silvia Helena. Contextos ecológicos: promotores de resiliência, fatores de risco e de proteção. Estudos de Psicologia, Campinas, v. 3, n. 25, pp. 405-416, 2008. Disponível em: <http://www.scielo.br/pdf/estpsi/v25n3/ a09v25n3.pdf>. Acesso em: 18 fev. 2013.

POLETTO, Michele. Bem-estar subjetivo: um estudo longitudinal com crianças e adolescentes em situação de vulnerabilidade social. 2011. 171f. Tese (Doutorado em Psicologia) - Universidade Federal do Rio Grande do Sul, Porto Alegre. 2011.

PRATI, Laíssa Eschiletti. Práticas dos terapeutas familiares brasileiros: a perspectiva da abordagem bioecológica do desenvolvimento humano. 2009. 149f. Tese (Doutorado em psicologia) - Universidade Federal do Rio Grande do Sul, Porto Alegre, 2009. Disponível em: <http://www.lume.ufrgs.br/bitstream/handle/10183/ 15870/000691715.pdf?sequence=1>. Acesso em: 19 abr. 2013.

SANTANA, Juliana Prates; KOLLER, Silvia. Introdução à abordagem ecológica do desenvolvimento humano. In: KOLLER, Silvia Helena (Org.). Ecologia do desenvolvimento humano. São Paulo: Casa do Psicólogo, 2004. pp.109-119.

SILVA, Adriana Nunes. Famílias especiais: resiliência e deficiência mental. 2007. 107 f. Dissertação (Mestrado em educação) - Pontifícia Universidade Católica do Rio Grande do Sul, Porto Alegre, 2007. Disponível em: <http://tede.pucrs.br/tde_ busca/arquivo.php?codArquivo=1216>. Acesso em: 25 abr. 2013.

SOUZA, Marilene Proença Rebello. Medicalização na educação infantil e no ensino fundamental e as políticas de formação docente. 2012. Disponível em: <http:// www.anped.org.br/reunioes/31 ra/4sessao_especial/se \%20-\%2012\%20-\%20 
marilene $\% 20$ proena $\% 20$ rebello\%20de $\% 20$ souza $\% 20$ - $\% 20$ participante.pdf>. Acesso em: 30 jul. 2013.

YIN, Robert K. Estudo de caso: planejamento e métodos. Porto Alegre: Bookman, 2001.

YUNES, Maria Angela Mattar. A questão triplamente controvertida da Resiliência em famílias de baixa renda. 2001. 168f. Tese (Doutorado em psicologia) - Pontifícia Universidade Católica de São Paulo, São Paulo, 2001. Disponível em: <http://www. msmidia.com/ceprua/furg/trab18.pdf>. Acesso em: 3 abr. 2013.

Recebido em maio de 2014

Aprovado em dezembro de 2014

Jane Ester da Silva Bazoni é mestre em educação pela Universidade Estadual de Londrina e professora da Rede Pública Municipal de Londrina. E-mail: janeester22ahotmail.com

Francismara Neves de Oliveira é doutora em educação pela Universidade de Campinas (UNICAMP), pós-doutorado em educação pela Universidade de São Paulo (USP), professora associada do Departamento de Educação da Universidade Estadual de Londrina (UEL) e do programa de pós-graduação em educação da UEL. E-mail: francis.uelagmail.com 